\title{
Um Adão biotecnológico: sobre a secularização dos antigos ideais religiosos pelo trans-humanismo
}

\author{
A biotechnological Adam: on secularization of \\ ancient religious ideals by the transhumanism
}

\section{Jelson Roberto de Oliveira*}

Pontifícia Católica do Paraná, Curitiba, Paraná, Brasil

\section{Resumo}

0 presente artigo pretende analisar o processo de secularização dos antigos ideais religiosos por parte das chamadas tecnologias convergentes ligadas ao Enhancement Project [Projeto de aprimoramento] e, mais especificamente, ao trans-humanismo. Para isso, partimos de uma breve apresentação retrospectiva do movimento e de suas principais premissas, destacando as intenções de melhoramento do ser humano a partir da diluição das fronteiras entre terapia e aperfeiçoamento por parte da biotecnociência contemporânea. A seguir, analisaremos como a tecnologia se utiliza de argumentos próprios do mundo religioso: [1] o poder tecnológico do ser humano é de tipo divino; [2] a própria tecnologia assume uma face divina; [3] oferece um sentido último para a vida e, consequentemente, [4] funda uma nova escatologia. Pretende-se, assim, não apenas

* JRO: Doutor em Filosofia, e-mail: jelson.oliveira2012@gmail.com 
mostrar a importância de que a filosofia e teologia levem em conta os desafios trazidos por esse cenário, mas também demonstrar o quanto as suas premissas fazem com que essas duas áreas se reencontrem com alguns dos seus temas fundamentais.

Palavras-chave: Trans-humanismo. Convergência tecnológica. Melhoramento. Enhancement Project.

\section{Abstract}

This paper aims to analyze the process of secularization of old religious ideals by the converging technologies operating in Enhancement Project and, more specifically, in Transhumanism. For this, we start with a brief retrospective presentation of the movement and its main assumptions, highlighting the improvement intentions of human beings from the blurring of boundaries between therapy and enhancement by the way of contemporary biotechnoscience. Next, we will examine how technology uses the arguments of the religious world: [1] the technological power of the human being is divine; [2] the technology itself takes on a divine face; [3] it offers an ultimate meaning to life; and hence, [4] establishes a new eschatology. The aim is thus not only to show how important it is that philosophy and theology take into account the challenges posed by this scenario, but also to demonstrate how its premises make these two areas reunite with some of their key issues.

Keywords: Transhumanism. Technological convergence. Improvement. Enhancement Project.

\section{Introdução}

A tecnologia privatizou e laicizou o debate sobre as questões últimas do sentido da vida, antes assunto de cunho religioso e filosófico. $\mathrm{O}$ trans-humanismo é uma forma de niilismo na medida em que emerge da crise das grandes religiões, das filosofias de cunho metafísico e das ideologias políticas de tipo utópicas, vindo a formular respostas e alternativas sobre a condição humana a partir da negação de qualquer ideia 
de "essência" ou de "natureza", o que possibilita que a tecnologia assuma a tarefa de "reforma" do homem, embora lhe falte uma "imagem" ou um "modelo" para tanto. O Enhancement Project [Projeto de aprimoramento], que pretende melhorar o ser humano, parte de uma decepção com o atual estado da humanidade tal como ela evoluiu da natureza ou derivou do ato criador de Deus. Nesse contexto, a própria condição humana é considerada uma condição doentia, que precisa ser tratada por meio das terapias de aperfeiçoamento biotecnológico que caracterizam a tarefa de autotranscendência do ser humano, com o objetivo de obter total controle sobre os pretensos limites impostos pela natureza, que incluem elementos de mistério sobre o nascer e o morrer, até agora associados à tradição religiosa, mesmo aquela que se associou ao humanismo moderno. O trans-humanismo, assim, se movimenta no cenário niilista da suposta falência dos ideais tradicionais, incluídas aí não só questões concernentes à identidade do homem, mas também sobre sua relação com a natureza e sobre sua ação na história.

\section{0 que é trans-humanismo}

O trans-humanismo pode ser descrito como uma filosofia (muitas vezes revestida de ideologia) que endossa as promessas do aperfeiçoamento que almejam transformar o humano em um pós-humano por meio da tecnologia. Trata-se de um pensamento que assume contornos teóricos e debates acalorados tanto no mundo acadêmico quanto no cotidiano da sociedade contemporânea, na medida em que é assumida por vários âmbitos da cultura, desde o cinema até a indústria pornográfica que, apoiados por impressionantes campanhas de marketing, mostram-se dispostos a projetar um futuro melhor para o ser humano. Francis Fukuyama, um notório crítico desse movimento, chegou a afirmar que o trans-humanismo "é a ideia mais perigosa do mundo" (2004), afirmação rapidamente rebatida por Nick Bostrom, um dos mais conhecidos militantes trans-humanistas ${ }^{1}$. Hottois $(2014$, p. 8) não deixa de reparar que a ideia de "transcendência material tecnológica" do homem recupera uma

1 Texto disponível em: <http://www.nickbostrom.com/papers/dangerous.html>. 
tradição que remonta tanto às fantasias alquímicas quanto ao gnosticismo e outras ideias mitológicas que transpassam a cultura humana e que agora assumem um viés biotecnológico, com êxitos práticos cujos efeitos dizem respeito ao âmbito da bioética, da biopolítica e mesmo da teologia.

A visibilidade pública do trans-humanismo adveio a partir da publicação de alguns relatórios americanos e europeus a respeito das possibilidades de melhoramento do ser humano como resultado daquilo que passou a ser conhecido como "convergência tecnológica", que inclui a nanotecnologia, a biotecnologia, as tecnologias de informação e as ciências cognitivas (nano-bio-info-cogno), que passam a agir de forma interconectada a favor de seus objetivos melhorísticos. O primeiro desses relatórios é de 2002. Publicado nos Estados Unidos sob o título Converging Technologies for Improving Human Performance. Nanotechnology, Biotechnology, Information Technology and Cognitive Science (CT-NBIC), ele foi seguido pela publicação de um segundo relatório, em 2004, dessa vez por parte da União Europeia, intitulado Converging Technologies - shaping the future of European Societies, que se opunha à euforia que marcava o documento norte-americano em torno das chamadas "ambições trans-humanistas" e anunciava que tal tarefa não deveria ser assumida como prioritária e que as tecnologias deveriam ser mantidas em seu uso exclusivamente terapêutico. Em 2009 um novo relatório é publicado pelo Parlamento Europeu sob o título Human Enhancement, no qual são diluídas as diferenças entre terapia e melhoramento e que reconhece o trans-humanismo como um "ator importante no debate em todos os níveis filosófico-religioso, ético, político” (HOTTOIS, 2014, p. 19) e como uma espécie de continuação dos ideais iluministas, da modernidade progressista e do humanismo laico. Desde então, enquanto o trans-humanismo se consolida como uma ideologia que milita a favor do melhoramento biotecnológico do ser humano (e até da vida em geral, tendo em vista suas teses sobre a obrigação moral de melhorar também os animais), vários relatórios e textos foram publicados como resultado de conferências e do trabalho de comissões de governos e da sociedade civil.

A aparição do termo trans-humanismo, contudo, é bem mais antigo e está associado ao biólogo e escritor inglês Julian Huxley (1887-1975), irmão de Aldous Huxley, primeiro diretor geral da UNESCO e presidente 
da Sociedade Eugenística Inglesa, e alguns de seus amigos, como J. B. S. Haldane (1892-1964) e J. D. Bernal (1901-1971). A versão inicial de Huxley acentuou, com o uso do termo, a perspectiva de transcendência e de realização de novas possibilidades para a natureza humana. Alguns especialistas (RANISCH; SORGNER, 2014, p. 9) apontam, inclusive, que Teilhard de Chardin (1881-1955) tenha, antes de Huxley, lançado as bases para o pensamento trans-humano, principalmente em sua obra $\mathrm{O}$ fenômeno humano, de 1955 (que, aliás, contou com a ajuda de Huxley para ser publicado postumamente). O termo, contudo, não demorou a ganhar conotações futuristas: em meados dos anos 1960 Fereidoun M. Esfandiary (1930-2000), que mais tarde mudaria seu nome para FM-2030, criou o grupo futurista chamado Up-Wingers, responsável pela popularização do trans-humanismo (principalmente com o livro Are you transhuman? de 1989). FM-2030 fez isso na New School for Social Research, em Nova York, na mesma época em que Hans Jonas lá trabalhava (1955-1976). Ele é reconhecido como precursor do trans-humanismo atual, que hoje conta com autores como Natasha Vita-More (cujo nome verdadeiro é Nancie Clark), autora do Transhuman Manifest, de 1983; Robert Ettinger, autor de Man into Superman, de 1972; e Max More (marido de Natasha Vita-More), fundador do antigo Extropy Institute, hoje diretor da Alcor Life Extension Foundation, provavelmente o mais famoso centro de criogenia ${ }^{2}$ do mundo.

Atualmente muitos dos seus teóricos estão articulados pela The World Transhumanist Association (WTA) ou pela Humanity+ $(\mathrm{H}+)$, uma organização sem fins lucrativos responsável pela popularização das ideias trans-humanistas ao redor do mundo, do qual o casal More é habitué. Nick Bostrom, fundador do WTA, juntamente com David Pearce, é diretor do Future of Humanity Institute, da Universidade de Oxford, e com James Hughes fundou o IEET (Institute for Ethics of Evolution and Technology, responsável pela publicação do Journal of Transhumanism). É preciso acrescentar, nesse rápido levantamento, o nome de Raymond Kurzweil, antigo estudante do MIT cofundador da Singularity University, com base na

2 Estudo que visa a produção de temperaturas muito baixas, com o intuito, no caso humano, de preservar os corpos congelados até que a ciência descubra uma cura para a morte e as informações genéticas ali guardadas possam ser transferidas para outros "organismos" ou “máquinas". 
NASA Research Park, no Vale do Silício, autor do livro The age of intelligent machines (1990) e sua atualização de 2005, The Singularity is near: when humans transcend biology.

Tal "institucionalidade" do movimento trans-humanista indica acordos e consensos tácitos presentes nos discursos de seus arautos, que se organizam em vários outros institutos e associações ao redor do mundo e despertam a atenção de muitos profissionais da medicina e de bioeticistas, tanto dos bioliberais quanto dos chamados bioconservadores. Mesmo que não formem um grupo homogêneo, os trans-humanistas compartilham o ideal de que o poder da tecnologia deve ser usado a favor do que eles entendem e praticam como aperfeiçoamento do homem e do meio ambiente - algo que seria não apenas desejável mas também eticamente obrigatório. Nessa medida, o "trans-humanismo pode ser descrito como um discurso tecno-otimista" (RANISCH; SORGNER, 2014, p. 14) e seus defensores como "tecnoprofetas" (HERBRECHTER, 2013, p. 46).

\section{Enhancement Project: a pretensão de melhoramento do ser humano}

A perspectiva trans-humanista foi bem resumida por Michael Hauskeller, para quem a projeção do humano em direção ao futuro parte da convicção de que "a condição presente da humanidade é inteiramente deplorável e, de fato, um estado doentio” (2015, p. 131). Isso significa que o homem do presente não passa de um ser ontologicamente enfermo para o qual a biotecnologia se apresenta como uma cura; em outras palavras, que a própria humanidade é a doença que a tecnologia precisa curar. Nesse sentido, o projeto de aperfeiçoamento passa a ser difundido como uma espécie de obrigação moral e o trans-humanismo ganha aparências de uma medicina para a humanidade. Isso significa que a antiga pergunta sobre a função da medicina, do modo como foi formulada, por exemplo, por Hans Jonas, na obra de 1985, Técnica, medicina e ética (especialmente no capítulo sétimo, que trata da "arte médica e responsabilidade humana”), deixa de ter sentido: já não há mais diferença entre terapia e aperfeiçoamento, ou entre cura e aprimoramento do ser humano ou, ainda, entre reparar uma disfunção e melhorar uma função. 
As projeções de Jonas, suas dúvidas e suas preocupações quanto à ética dessas pesquisas nunca foram tão atuais. Segundo ele, se antes, a arte médica - hoje revestida com os novos rótulos tecnológicos - deixou de ser uma "arte da cura", ou seja, o "restabelecimento de um estado" $\left(\mathrm{PR}^{3}, 155\right)$ que não era, ele mesmo, alterado, mas ao contrário, mantido como um "estado natural ou tão próximo a ele quanto possível" (PR, 155), agora a medicina se apresenta como uma alteração da própria natureza humana. O médico não é mais aquele que cura, mas "o artista do corpo com fins abertos" (PR, 159), agindo na "incerteza de nosso conhecimento sobre o sentido da existência humana" (PR, 170), aparelhado por uma "vontade de ilimitado poder" (TME, 34). Para o projeto de aperfeiçoamento, portanto, a chamada cura da humanidade evoca, de um lado, um sentido ético: é preciso curar a humanidade de si mesma; e, de outro, um sentido ontológico: curar não é restabelecer algum estado natural perdido, mas superar os limites impostos pela natureza. Trata-se de uma substituição da antiga ideia regulativa da medicina como restitutio ad integrum (restabelecimento de uma integridade) pela ideia de transformatio ad optimum (a remodelagem de pessoas que já estão em estado de saúde, mas que pretendem melhorar certas características; uma pretensão que pode ser resumida na ideia de "editar" a vida, ou seja, consertar os erros, incrementar características desejáveis e inserir novas capacidades). Bert Gordijn e Ruth Chadwick, no volume por eles organizado sobre Medical Enhancement and Posthumanity (2008) apresentam esse fenômeno de mudança no papel da medicina como sendo, propriamente, o que se chama de Enhancement Project, ou seja, o projeto de aprimoramento (ou mesmo de aperfeiçoamento, levando em conta que a finalidade dos expedientes seria levar os seres à perfeição).

Obviamente, a tentativa de otimizar e aperfeiçoar o ser humano não é nova. O que é novo são os instrumentos que colocam o ser humano contemporâneo bastante próximo de várias daquelas promessas que até

3 Usaremos nesse artigo as siglas convencionais para a citação das obras de Hans Jonas: PR ( 0 princípio responsabilidade); TME (Técnica, Medicina e Ética); e SDD (para o ensaio 0 século dezessete e depois: 0 significado da revolução científica e tecnológica). Seguindo a sigla referente ao título da obra, está o número da página. Para os demais autores, seguiremos o sistema autor-data. À exceção das obras PR e TME, todas as demais citações foram traduzidas por nós a partir das obras disponíveis nas referências. 
então não passavam de fantasias. Na Antiguidade, a saúde era vista como uma espécie de equilíbrio orgânico e o papel do médico era impedir os distúrbios e reinstalar a ordem original, transformar a discrasia em eucrasia do microcosmos humano. Nesse sentido, como propõe Wiesing (2008, p. 9) restitutio ad integrum era uma forma de restitutio ad optimum, ou seja, restituir o que era bom do ponto de vista do equilíbrio. A medicina era uma arte (techné) de imitação da natureza (e não, como é agora, uma forma de controle sobre ela ou mesmo de superação). Essa ideia de medicina como mimesis foi predominante na maior parte da história ocidental, justificada pela grande influência do pensamento aristotélico até a modernidade. Do ponto de vista moral e religioso, "tornar-se como um Deus" (homoiosis theo), ou seja, aproximar os seres humanos da divindade (fazer com que o homem alcance a perfeição, como só Deus é perfeito) era uma tarefa da filosofia - e não da medicina. A perfeição estava ligada, para Platão, na República (352a-b) por exemplo, à virtude da justiça e, portanto, ao aprimoramento moral. Na Idade Média, marcada, como se sabe, pela ideia de um Deus onisciente e onipresente, a ideia de perfeição dizia respeito ao pertencimento do homem ao reino da criação: tudo o que foi criado, o foi em perfeição. São Tomás de Aquino afirma na sua Suma Teológica, por exemplo, que a perfeição do corpo é parte do trabalho artístico de Deus (q. 91, 3). Em sentido corrente, as doenças não seriam mais do que um desvio dessa perfeição, muitas vezes motivadas pelo pecado ou pela possessão de maus espíritos - as preocupações da medicina de então, em alguma medida, se encontravam com as teológicas e a integridade era reconhecida como uma harmonia entre o plano divino e o plano humano, um acordo entre a ordem natural e a vontade de seu criador. A restitutio ad optimum, nesse caso, seria cumprir plenamente o plano de Deus, algo que "só seria possível na vida depois da morte e somente através da misericórdia de Deus" (WIESING, 2008, p. 11).

Quando Paracelsus publica o seu De natura rerum, em 1537, obra na qual aparece pela primeira vez a ideia de um homunculus, ou seja, um ser criado em laboratório com auxílio da alquimia e com potencial de se tornar um super-humano (ideia vista mais tarde, pelos iluministas, como supersticiosa), alguma coisa começava a mudar. A era moderna é o tempo em que a humanidade assumiu para si a possibilidade de intervenção na 
natureza e, consequentemente, em si mesma. A mimesis aristotélica cedeu lugar, então, à criatividade e à invenção, compreendida como capacidade produtiva de interferência no mundo e como possibilidade ilimitada do fazer exploratório. Gordijn e Chadwick situam o início dessa mudança no século XVII, principalmente a partir de três autores: Francis Bacon e sua New Atlantis (1627); René Descartes, principalmente no Discours de la méthode pour bien conduire sa raison et chercher la vérité dans les sciences (1637); e Condorcet, com Esquisse d'un tableau historique des progrès de l'esprit humain (1795). Esses escritos teriam lançado as bases para a nova compreensão moderna da medicina em seu papel de aprimoramento (GORDIJN; CHADWICK, 2008, p. 1). Depois disso, como aponta Wiesing, a teoria evolucionária trouxe novos impactos sobre o modo de pensar a tarefa médica. Se a vida em geral e o homem em particular são resultados de mudanças no processo evolutivo, isso significa que o homem não é um produto perfeito, não está pronto de uma vez por todas, mas ao contrário, é uma soma de imperfeições, está "deficiente e predisposto a muitas deficiências", que são "produtos acidentais da história" (2008, p. 15). Algo que Nietzsche, por exemplo, reparou muito bem, já no primeiro aforismo de sua obra de 1878, Humano, demasiado humano, ao afirmar que o homem é fruto do vir-a-ser e não pode ser compreendido mais sob o dossel de uma filosofia metafísica, mas de uma "filosofia histórica, que não se pode mais conceber como distinta da ciência natural, o mais novo dos métodos filosóficos" (NIETZSCHE, 2000, p. 7). A filosofia, em outras palavras, para compreender o homem, não pode mais fechar os olhos para os dados da teoria evolucionista, que o apresenta como um ser sempre em mudança e, por isso, sempre predisposto ao risco de sua própria extinção. Se a sociedade do final do século XIX se viu, diante dessas teorias, ameaçada pela decadência, ela também foi capacitada a assumir o controle de seu próprio aprimoramento, já que as portas para isso estavam abertas em definitivo por meio da ideia de uma identidade/natureza/condição flexível, construída ao longo da história ${ }^{4}$. Não demorou para que ideias fossem

4 Até hoje muitos trans-humanistas acreditam que o aprimoramento é parte do processo evolutivo da espécie como um todo. 
assumidas pelos eugenistas ${ }^{5}$ como parte de seu projeto de aperfeiçoamento da espécie, algo que foi, como se sabe, gradualmente condenado depois de 1945, quando vieram à tona os abusos aos direitos humanos praticados pelo Nacional Socialismo, embora muitos esforços tenham sido impetrados para garantir certa legitimidade aos procedimentos nos anos subsequentes ao fim da segunda grande guerra, como demonstra a posição dos cientistas participantes do Simpósio CIBA, em Londres, em 1962. A maioria dos 27 cientistas de ponta (entre os quais 6 prêmios Nobel) que participaram desse evento falaram a favor da eugenia. No geral a ideia era de que o ser humano devia ser alterado como forma de superação da recente crise da humanidade, algo que dava à ciência um poder absoluto para erradicar todos os problemas humanos.

Para Gordijn e Chadwick (2008) é preciso notar duas grandes diferenças entre o pensamento filosófico do século XVII e XVIII e aquele que se desenvolve em nossos dias na forma do trans-humanismo: a primeira diz respeito ao fato de que, em nossos dias, cada vez mais a medicina vem sendo percebida como potencialmente eficaz para o aprimoramento do ser humano e a segunda, ao seu poder efetivo de realizar o que se propõe perante uma considerável história de êxitos.

Quanto ao primeiro elemento, é preciso notar como as ciências médicas estão sendo vistas com otimismo pela sociedade em geral, um otimismo que se desdobra em três níveis: [1] nos êxitos da biologia, da química e da física em conhecer e intervir no meio ambiente em geral a fim de moldá-lo segundo os interesses humanos; [2] nas crenças em uma sociedade perfeita, desenvolvida no campo da história, da sociologia e das teorias políticas, para cujo processo os controles de humor e de comportamento, por exemplo, seriam de fundamental importância; [3] nos progressos alcançados até agora no âmbito do controle e da edição do corpo humano segundo um ideal (bastante duvidoso) de perfeição da natureza humana, nascido da acoplagem da medicina com a biotecnologia. Obviamente, um tal otimismo vem encontrando vários obstáculos, devido tanto às críticas teóricas que esse projeto vem recebendo quanto aos fatos cotidianos que mostram que os processos tecnológicos vêm causando

50 seu fundador teria sido, não por acaso, um primo de Charles Darwin, Francis Glaton (1822-1911). 
inumeráveis prejuízos do ponto de vista ambiental: "mais e mais, torna-se claro que o esforço para melhorar radicalmente nossas sociedades pode ter severas e incontroláveis desvantagens" (GORDIJN; CHADWICK, 2008, p. 2). Um esforço, diga-se de passagem, que passou por muitas utopias políticas (leninismo, stalinismo, maoísmo e nazismo) que marcaram o século vinte e que fracassaram, dando origem ao clima distópico ou antiutópico difundido na consciência pública mundial por autores como Orwell, Zamyatin e Huxley. Nesse sentido, embora a sociedade se torne mais cética em relação aos benefícios das intervenções no meio ambiente ou no âmbito político-social, ela parece ainda bastante entusiasmada com os avanços no campo da medicina, muitos dos quais vêm despertando considerável interesse intelectual e científico em nossos dias. A medicina passa a ser, agora, o reduto das esperanças e utopias perdidas no campo político e religioso. Nesse sentido, parece que as desilusões referentes à possibilidade de domínio sobre a natureza e à modelagem de sociedades ideais acabaram por "reforçar o entusiasmo acadêmico em relação à ideia de perfeição" do ser humano (GORDIJN; CHADWICK, 2008, p. 3). Ao que parece, isso ocorre porque se acredita ser preciso primeiro aperfeiçoar o homem para, depois, aperfeiçoar a natureza e a sociedade ao redor; ou seja, porque o fracasso das duas primeiras tentativas se deve ao fato de que o seu agente era, ele mesmo, imperfeito e incapaz de realizar a tarefa cósmica que lhe coube. Ao entusiasmo científico e acadêmico, junte-se o apoio público que essas pesquisas vêm recebendo ao redor do mundo e os recursos financeiros que vêm captando, fazendo com que governos e companhias privadas vislumbrem em seus "resultados" lucrativos "produtos" que serão, sem dúvida, rapidamente inseridos na cadeia do consumo.

Quanto ao segundo elemento, ou seja, aos poderes efetivos para que as promessas da medicina sejam cumpridas e os interesses e entusiasmos satisfeitos, é inegável que muita coisa mudou desde o século XVII. Todos os campos da vida real estão sendo afetados pelos novos poderes seja no campo da clínica (cirurgias cosméticas, medicina esportiva, engenharia de tecidos, psicofármacos e bioeletrônica), seja no campo da pré-clínica (clonagem, células-tronco, engenharia genômica e intervenções de todo tipo no âmbito dos processos biológicos), seja até campos ainda mais profundos e ignotos, como o da nanotecnologia, da biologia sintética ou de pesquisas 
sobre inteligência artificial e suas potenciais conexões com o ser humano. Nesse sentido, o aprimoramento humano vem aparecendo como algo bastante realista, dada a sua difusão em todos os âmbitos da cultura: "os melhores exemplos disso são o uso de esteroides anabólicos no esporte, todo tipo de intervenções cirúrgicas cosméticas e o uso de Prozac, Ritalina e Viagra com propósitos não terapêuticos" (GORDIJN; CHADWICK, 2008, p. 3), ou seja, as lifestyle drugs. Estamos caminhando, de fato, para o momento em que não será mais possível falar em "ser humano" enquanto tal, em que não se saberá mais do que se trata quando se refere a um "ser humano", dadas as suas inúmeras variações e tão radicais intervenções em sua "natureza". Nesse caso, passaríamos da transformatio ad optimum para uma transformatio ad infinitum, como sugere Wiesing (2008, p. 20).

Um tal otimismo não é estranho: muitos autores apontam os benefícios desses procedimentos e em muitos casos eles parecem bem evidentes. Tais posições tendem a relativizar o problema da "natureza" humana ou da sua identidade ou essência, ou mesmo acreditam que a gestão da herança genética da vida passa, necessariamente, pelo seu aprimoramento, algo que se torna uma espécie de obrigação moral. As engenharias genética e bioeletrônica podem contribuir imensamente, por exemplo, para o aprimoramento das capacidades motoras, sensoriais e cognitivas. A terapia somática genética pode evitar muitas deficiências nas futuras gerações. A transferência da mente humana para um computador poderia abrir caminho para a cura da morte. Outras tantas intervenções podem retardar ou mesmo cancelar o envelhecimento. Ainda que seja possível sempre reconhecer algum "bem" nesses procedimentos e nas suas promessas, é necessário, contudo, manter uma espécie de suspeita em relação a seus benefícios em longo prazo. O pano de fundo central dessa preocupação deve ser a pergunta de cunho ético, sobre os valores que orientam esse processo. Seria preciso, por exemplo, pensar sobre a metafísica dos valores, sobre o fato de que eles não estão dados de uma vez por todas e sobre o fato de que o "bem" e o "mal" podem não estar definitivamente fixados e talvez nem o possam ser, sobre a historicidade dos valores e suas reiteradas transformações no âmbito das diferentes culturas e dos diferentes períodos históricos. Trata-se, enfim, de problematizar decisões tão incontornáveis para o futuro da humanidade, sobre o que ela deve ser ou sobre que é o seu bem ou o seu melhor. Estamos, 
novamente, diante das chamadas "questões últimas", embora sua formulação e seu enfrentamento dispensem os instrumentos teóricos fornecidos pela filosofia e pela teologia, substituídas agora pelo afã utópico das tecnologias convergentes.

\section{Um homem que se fez Deus}

A afirmação central do trans-humanismo é de que o homem não possui uma essência e que sua condição não é, de maneira alguma, imutável, o que significa que ele poderia ser alterado pela tecnologia com ampla permissividade. Esse é um primeiro aspecto antropológico niilista que persiste no movimento trans-humanista. Um segundo aparece como desdobramento desse primeiro: se não há uma essência, e se os seus arautos reconhecem o aperfeiçoamento tecnológico como um imperativo ético, falta-lhes um modelo ou uma imagem segundo a qual a tecnologia poderia reconfigurar o homem e as demais espécies. Ou seja: se é necessário recusar a ideia de uma essência humana para que os expedientes tecnológicos de aperfeiçoamento sejam executados, o custo dessa abdicação é justamente deixar o próprio serviço sem horizonte, meta ou objetivo. Atirada a si mesma, a técnica se vê enredada em um processo constante e nunca saturado de busca por novos poderes, amparada por uma crença utópica na ideia de progresso e de poder ilimitado. Falta-lhe o para que. E, sem um modelo que possa oferecer as bases para pensar o que é um ser humano melhor ou mesmo o que é uma planta ou um animal melhor, ela se perde na redundância dos experimentos, cujos perigos não são poucos. Hans Jonas chama esse processo de "neutralização metafísica da imagem de homem" (TME, 30).

A nova aposta na racionalidade tecnocientífica manifesta-se assim, como parte da vontade de poder que estacionou o homem na obrigação de alterar o mundo a seu favor. Com o anúncio da "morte de Deus", o homem toma para si a tarefa de reconfiguração do mundo e de si mesmo. Quais os valores que devem guiar o projeto de aperfeiçoamento do ser humano? Seria a própria ideia de aperfeiçoamento já o valor principal desse projeto? E se assim for, ele seria legítimo, ainda que não saibamos o que seja, de fato, um ser humano melhor ou perfeito? Mas... melhor ou perfeito em relação a quê? Sem essas referências, o trans-humanismo não passaria de 
um conjunto de experimentações cujo valor e fim não é outra coisa senão a própria experimentação. Nesse sentido, como apontou Sandberg (2015, p. 3) a própria exploração das possibilidades (algo que Jonas chamou de "aposta") torna-se o valor por excelência e o próprio "sentido da vida" no âmbito científico-tecnológico. Para Sebastian Seung, essa perspectiva faz com que a meta da vida seja a própria transcendência da condição humana:

O sentido da vida inclui tanto a dimensão universal quanto a pessoal. Nós podemos perguntar "Estamos aqui por alguma razão?" e também "Eu estou aqui por alguma razão?”. O Trans-humanismo responde essas questões da seguinte maneira. Primeiro, é o destino da humanidade transcender a condição humana. Isso não é apenas o que vai acontecer, mas o que deveria acontecer. Segundo, pode ser um objetivo pessoal se inscrever na Alcor, sonhar com a transferência para uma máquina ou usar a tecnologia para melhorar a si mesmo. Em ambos os casos, o trans-humanismo empresta um sentido de viver que tinha sido roubado dele pela ciência.

A Bíblia diz que Deus fez o homem à sua própria imagem. O filósofo alemão Ludwig Feuerbach disse que o homem fez Deus à sua própria imagem. Os trans-humanistas dizem que a humanidade vai fazer de si mesma Deus (SEUNG, 2012, p. 273).

O que está em jogo, portanto, é assumir a posição antes ocupada pela divindade e isso passa a ser reconhecido como o valor e a finalidade da vida como um todo. O trans-humanismo, assim, afirma a si mesmo, em seu afã de aperfeiçoamento tecnológico, como destino da humanidade, concretizando o que Jonas afirmara: "a tecnologia é mais forte do que a política. Tornou-se o que Napoleão pensava a respeito da política: um destino" (SDD, 120). Algo que assume o caráter de uma "escatologia secularizada do novo Adão", ou seja, a ideia de reconfigurar o homem e tratar a condição humana tal como ela tem sido até agora como um medo "produto de circunstâncias constrangedoras e deformantes" (PR, 287). O "novo Adão" seria resultado da tecnologia, ela mesma vista como uma "segunda vinda" do Messias, agora recuperado da queda na imperfeição e elevado pelas novas circunstâncias promovidas pela técnica, azeitada pelas utopias políticas, cuja missão é "substituir o milagre divino por causas mundanas" (PR, 287). As palavras de Jonas se dirigem à utopia marxista que, semelhante à capitalista, estaria amparada na promessa de salvação do homem através da produção e do 
trabalho. Elas repercutem, contudo, no âmbito geral das utopias, que passam a gerenciar de forma evidente todo o fazer tecnológico do Enhancement Project divulgado pelo trans-humanismo.

Nesse sentido, o trans-humanismo dá nova expressão ao "além" religioso na medida em que pretende criar artificialmente as circunstâncias capazes de melhorar o homem, algo que exige afirmar que tais circunstâncias (adequadas ao melhoramento) não existiram até agora, pois, ao longo de sua história, o homem não foi o que deveria ter sido, não foi perfeito o suficiente, não realizou o seu destino. A crítica de Jonas a Bloch, em $O$ princípio responsabilidade, poderia ser reeditada em nova perspectiva pois, de alguma forma, o trans-humanismo não só profetiza a esperança, como reafirma a crença no "homem verdadeiro" e no poder tecnológico capaz de fabricá-lo a partir de agora. A "ontologia do "não ser ainda"” (PR, 337) de Bloch permanece no trans-humanismo, na medida em que seus arautos afirmam que aquilo "que tudo o que o homem pode e 'deve' ser não aconteceu até agora, podendo apenas acontecer no futuro" como produto da "continuação ininterrupta do desenvolvimento atual" (PR, 337), um progresso que, em última instância, levaria à reforma da própria "essência dos indivíduos" e da própria "natureza dos homens" - algo que Jonas parece ter apenas intuído. Como utopia radical, o trans-humanismo nega que o homem verdadeiro tenha existido ou que ele exista. Antes, o homem perfeito, como homem melhor, é o homem verdadeiro que será fabricado de forma artificial pelo poder tecnológico. A ontologia do "não ser ainda" de Bloch, cuja fórmula central é "S ainda não é $P$ (o sujeito ainda não é seu predicado)" (PR, 338) se desdobra na afirmação radicalmente utópica do trans-humanismo a respeito das possibilidades abertas para o aprimoramento do homem, esse "ser inacabado" cuja meta está em aplicar sobre si mesmo o poder adquirido, com o objetivo de finalizar o que as eras da evolução (ou Deus, se se quiser) não foram capazes de fazer. O homem até agora foi só uma "tendência-latência" ou seja, ele apenas guardou a vontade de se tornar algo melhor: pulsa em $\mathrm{S}$ o desejo de se tornar $\mathrm{P}$ e é esse desejo que alicerça e legitima sua tarefa tecnológica.

$\mathrm{Na}$ linguagem trans-humanista de Ramez Naam, isso significa "um novo gênesis": "Nós somos, se escolhermos ser, a semente de onde maravilhosos novos tipos de vida podem crescer. Nós somos os parentes 
prospectivos de novas e inimagináveis criaturas. Nós somos o minúsculo metazoário do qual um novo cambriano pode brotar". E acrescenta, sem esconder seu entusiasmo: "Eu não posso pensar em um destino mais lindo para qualquer espécie, nenhum lugar mais privilegiado na história do que ser os iniciadores de um novo gênesis" (2005, p. 232). Eis por onde a humanidade assume a sua tarefa cósmica, a partir do reconhecimento de sua própria contingência como parte do processo de aparecimento de novas espécies. Intervindo sobre si mesmo, o homem atual deixaria de ser um fim em si para tornar-se um simples meio para o desenvolvimento de espécies mais elevadas e perfeitas, em nome da diversidade. A negação da finalidade do homem é assumida, nesse caso, como uma negação do valor próprio do humano e de sua integridade diante da criação. Nada do que fomos até agora se compararia a essa nova tarefa, assumida com euforia por seus arautos.

\section{0 cristianismo é um trans-humanismo? Deus é tecnológico?}

Sandberg (2015, p. 4) evidencia, contudo, que a questão não é tão simples. Ao separar o trans-humanismo em três perspectivas (individual, terrestre e cósmica) ele mostra como a questão sobre o sentido da vida pode ser mais complexa. Do ponto de vista individual, muitos trans-humanistas parecem não concordar, de fato, com a ideia de que existe um sentido para a vida, ao contrário, muitos parecem assumir uma posição existencialista ao afirmar que, do ponto de vista individual, o sentido da vida é uma escolha de cada um ou, dito de outra forma, que decidir o próprio rumo é o sentido da vida. Trata-se de aproveitar as oportunidades e, para isso, é preciso ampliar as possibilidades. Muitos chegam a reivindicar, inclusive, a ausência de valor como própria do movimento trans-humanista e, mesmo quando assumem a necessidade de superar as limitações biológicas do homem presente, "eles não defendem que haja um objetivo em si mesmo, apenas que essa é a condição a partir da qual outros objetivos e experiências devem ser ainda mais ampla, permanente e expansivamente perseguidas" (HOPKINS apud SANDBERG, 2015, p. 6). Há posições divergentes. Uma delas é a de Micah Redding, que afirma que o "cristianismo é um transhumanismo" na medida em que elege como objetivo "fazer o trabalho de Deus", isto é, que a tecnologia é, na 
verdade, expressão do poder divino que empodera o homem em busca de sua própria transcendência. Há quem seja mais específico: o Movimento Terasem, por exemplo, criado em 2004 pelo advogado e escritor norte-americano Martin Rothblatt (que em 1994 assumiu sua condição transgênera, passando a se chamar Martine Aliana Rothblatt e tornando-se uma importante militante dos direitos transgêneros) apresenta-se como uma escola do pensamento trans-humanista cuja pretensão é desenvolver "uma consciência coletiva dedicada à diversidade, unidade e alegre imortalidade" por meio de uploading da mente (transferência para um computador) e do que eles chamam de geoética nanotecnológica. Os membros da Terasem assumem suas crenças como "transreligiosas", a partir de quatro afirmações centrais: a vida é proposital; a morte é opcional; Deus é tecnológico; amor é essencial (TERASEM, 2002/2012). Entre outras coisas, o movimento pretende oferecer um serviço capaz de carregar a consciência em uma máquina ou em um corpo bionanotecnológico como parte da conquista de longevidade ou até mesmo de cura da morte dos indivíduos. Não raras vezes criticadas como mero acúmulo de ilusões e de promessas insensatas, tais perspectivas sinalizam, contudo, para uma apropriação de discursos religiosos por parte dos movimentos trans-humanistas. Posições semelhantes são assumidas por outros teóricos, entre os quais os defensores do chamado "imortalismo universal", entre os quais está Mike Perry, para quem "a imortalização dos humanos e outras formas de vida é vista como um grande projeto moral e um trabalho de amor que nos unirá em uma causa comum e nos fornecerá um destino significativo" (apud SANDBERG, 2015, p. 16-17). A marca religiosa e humanista desse tipo de discurso é evidente.

Crenças semelhantes podem ser encontradas no Extropismo, um movimento criado no final dos anos 1980 (a palavra extropia é um antônimo de entropia) que, segundo Max More (um de seus idealizadores e presidente do Extropy Institute), projeta a "extensão da inteligência, informação, energia, vitalidade, experiência, diversidade, oportunidade e crescimento de um sistema vivo ou organizacional" (MORE, 1993). Para os extropistas, a razão científica pode "oferecer sentido e direção para nossas vidas" na medida em que busca o aprimoramento das condições vitais, superando a lentidão do processo evolucionário natural por meio de procedimentos 
tecnológicos capazes de acelerar e melhorar nossa inteligência. A expansão extrópica seria, assim, o destino do homem e o sentido mesmo de sua existência. Confessando a influência da ideia nietzschiana do Übermensch, More afirma que o extropismo é a tentativa de superação do homem e este, segundo a afirmação do próprio Nietzsche, seria "o sentido da terra".

O trans-humanismo, nessa medida, assume a antiga questão sobre o sentido da vida, até então um dos aspectos centrais do mundo religioso. Em seu livro de 1972, Man into superman, R. C. W. Ettinger, considerado o pai da criogenia, afirma que o sentido da vida é simplesmente "descobrir o sentido da vida" e, consequentemente, desenvolver todas as condições para isso, entre elas o aprimoramento da nossa inteligência, reconhecida como o principal instrumento de trabalho a favor do aperfeiçoamento humano. David Pearce, por outro lado, afirma que a inteligência pode nos tornar capazes de diminuir a dor e aumentar o prazer de todos os seres sencientes - esse sim reconhecido por ele como o objetivo da vida. Nick Bostrom segue na mesma direção, afirmando a importância de que o desenvolvimento mental do ser humano (conjugado ao aumento da expectativa de vida) seja a principal meta da vida. Sandberg não deixa de notar a proximidade dessas afirmações com o discurso religioso e que, muitas vezes, o próprio trans-humanismo é apresentado como uma espécie de religião, seja porque anuncia a transcendência da condição humana, seja porque "partilha com a religião muitos interesses metafísicos, soteriológicos e escatológicos" (2015, p. 5).

No geral o movimento trans-humanista considera que o aprimoramento do ser humano é o sentido da vida e isso envolveria o desenvolvimento de novas habilidades, o aumento da longevidade, o refinamento e controle das emoções, o aprimoramento das capacidades mentais e da saúde em geral, até mesmo a luta contra a finitude. Tais promessas soam como parte do leque de opções que deveria estar disponível para cada ser humano. É fácil, contudo, perceber que muitas dessas escolhas são, na verdade, falsas, na medida em que, embutidas em suas possibilidades, está o risco de negação da capacidade de escolha, a anulação das possibilidades. 


\section{0 mito do progresso contínuo: uma nova escatologia}

Curiosamente, a tecnociência é um lugar especial para a proliferação dos mitos e artigos religiosos no mundo contemporâneo e certamente o trans-humanismo é um dos seus terrenos mais férteis. Em The Myths we live by, a filósofa inglesa Mary Midgley sugere que os mitos continuam atuais, não como mentiras, mas como "padrões imaginativos, redes de poderosos símbolos que sugerem modos particulares de interpretar o mundo" (2003, p. 1). Nesse sentido, a tecnociência encantou-se com o canto da sereia que quis evitar e fez da desmitologização uma nova espécie de narrativa mítica. Ela constrói narrativas, expõe sentidos de mundo, organiza interpretações e influencia os comportamentos dos indivíduos contemporâneos. Uma das forças mais importantes para isso é o mito do progresso, sobre o qual Jonas se dedicou em seus estudos, demonstrando como ele é o motor central das utopias tecnológicas a partir da era moderna. Michael S. Burdett (2015, p. 132) afirma que "o mito do progresso pode ser definido como a crença de que a história/sociedade/humanidade avançou, continua avançando e avançará ainda mais no futuro". A lógica do incremento de poder na direção de um determinado ideal imaginado de mundo é a força que alimenta esse sistema e que serve de critério para avaliação do movimento, vindo a fundar um novo tipo de escatologia. Nesse modelo, tudo o que existe no presente não é mais do que algo que será melhor no futuro, porque ainda está marcado pela imperfeição, pela incompletude e por outros sinais de discrepância e desarmonia em relação ao ideal. Esse mito é alimentado do ponto de vista epistemológico por uma crescente descoberta do mundo natural, com o apoio de metodologias, disciplinas, práticas e instrumentos técnicos que desvelam as várias camadas da realidade em um movimento progressivo e aparentemente infinito. Jonas chama isso de "premissas ontológicas e gnosiológicas" (TME, 35) do progresso contínuo, algo que se torna uma convicção que é partilhada por todos os membros da comunidade científica bem como por qualquer cidadão atual: "pode haver um progresso ilimitado, porque sempre há algo novo e melhor a ser encontrado". É o mundo, enquanto condição objetiva, portanto, que exige da ciência a necessidade de um progresso em termos 
de conhecimento. A técnica, aliada com a ciência (que, segundo Jonas, é a marca da era moderna) vê a natureza como "algo cada vez mais sutil" (TME, 37), que pode ser investigado por equipamentos cuja inteligência desvela níveis de realidade sequer imaginados. A perspectiva niilista, contudo, revela-se como uma instauração e uma ruptura entre a ação e os objetivos da ação. O resultado é que, "ao invés de reduzir a margem do que resta para ser descoberto, a ciência surpreende a si mesma hoje com dimensão após dimensão de novas profundidades" (TME, 37). Assim, a própria ideia de matéria deixa de ser alguma coisa disponível para a pesquisa, ocupando algum lugar no espaço, para ser um "desafio aberto vez ou outra para dar acesso a uma sempre mais profunda penetração" (TME, 37). Trata-se de uma "investigação sem fim" com "giros sempre novos" que precisa ser retroalimentada: a técnica torna-se o objetivo da própria técnica porque a ciência precisa de instrumentos cada vez mais refinados. Dessas pesquisas vemos nascer outros terrenos de pesquisa, novos instrumentos, novas práticas e assim por diante. A técnica vira, para si mesma, uma "incubadora de novas perguntas" (TME, 38) em um "circuito sem fim", ou seja, ilimitado e desprovido de qualquer teleologia, em uma "mútua relação de feedback" que mantém tanto a ciência (enquanto atividade teórica) quanto a técnica (como atividade prática), em um movimento conjugado que chamamos de tecnociência. $\mathrm{O}$ modo dessa escatologia é, portanto, a negação de uma finalidade e a entrega a um movimento interminável de suposto melhoramento, camada após camada de realidade. Assim, o niilismo se veste da infatigabilidade gnosiológica proporcionada pela técnica. A vontade de verdade é impulsionada de forma infinita para todas as direções, em constante reciprocidade entre os dois campos, o do saber e o do fazer, que constituem o novo poder. Para Jonas, os sinais de agora apontam, se não para um avanço infinito desse apetite, pelo menos, "quanto a possibilidades e impulsos", para "uma direção e fertilidade indefinidas do impulso tecnológico". Isso porque a natureza das coisas dispostas no mundo evoca a "visão teórica" segundo a qual é preciso levar o conhecimento sempre adiante porque essas "coisas" "não põem limite algum ao descobrimento e invenção, mas ao contrário, abrem em qualquer ponto a partir de si mesmas um novo acesso a algo ainda por conhecer e por fazer" (TME, 35). Uma tal 
convicção se ampara na tecnologia, cujos instrumentos oferecem hoje a possibilidade de acessar essas novas realidades sem nenhum tipo de freio, já que nunca ocorre o "esgotamento interno das possibilidades", ou seja, sempre há algo para se conhecer depois do que já foi conhecido. Jonas se refere a esse processo como uma "fé inteiramente sem precedentes na 'infinitude' virtual" (TME, 36) e é esse o "impulso mais íntimo da dinâmica tecnológica", cuja base é a abertura de um caminho sem fim de novos e sucessivos passos.

Como mito, esse processo nos engaja de forma subjetiva e existencial, como demonstrou Burdett (2015, p. 134) na medida em que suas bases são também de tipo religioso e a partir delas é possível projetar sentidos para a própria vida, ainda que de uma forma bastante diferente do passado. Burdett explica, além disso, que o mito do progresso tem raízes muito antigas, que podem remeter à mitologia grega, aos sofistas e/ou a Platão, mas também ao cristianismo e ao Iluminismo. Na época moderna, o programa baconiano é reconhecido por Burdett, mas também, antes, por Jonas, como embrião do mito moderno do progresso como um novo estado de harmonia plena, nascido da conjunção de saberes com poderes que, somados, fariam do mundo um lugar melhor para se viver. No seu Instauratio Magna Bacon se refere a essa realidade como uma "restauração das capacidades adâmicas básicas perdidas na Queda do homem, empregando um novo método de acúmulo de informação sobre o mundo natural" (BURDETT, 2015, p. 135). Algo que, afinal, se revela completamente na utopia da Nova Atlântica. Bacon simboliza, por isso, a associação definitiva da ciência com o mito do progresso, realizado como utopia, algo que se desenvolverá no século XIX pelas tintas de Comte, Mill, Hegel e 
Marx, ganhando formas que fizeram do progresso a "psyche do tempo" (BURDETT, 2015, p. 137), mesmo sob as fortes críticas de Kierkegaard e de Nietzsche. Se o século XVIII tinha feito da liberdade o grande bastião de uma época, o século seguinte viu florescer a ideia de progresso como imagem-símbolo dos ideais coletivos e individuais, fruto do esforço humano (científico e tecnológico) em substituição à providência divina.

Depois dos tempos distópicos que se seguiram à Primeira Guerra Mundial, à Grande Depressão e aos horrores da segunda grande guerra, o mito do progresso apareceu com força redobrada na utopia tecnológica e no trans-humanismo, especialmente a partir das últimas três décadas do século passado. Burdett analisa essa ascensão a partir da imagem emblemática de Alexander Leydenfrost, publicada na revista Popular Mechanics, de 1952, apenas sete anos depois da Segunda Guerra Mundial, como parte de um artigo cujo título era "A ciência em marcha”. A imagem mostra a ascensão tecnológica de 1902 até 2002 (cem anos, portanto), com representação de todo tipo de projeções futuristas que hoje estão associadas aos ideais capitalistas. Para Burdett (2015, p. 142) o trans-humanismo é uma radicalização do mito do progresso presente nessa imagem.

6 Burdett lembra do quadro de John Gast, intitulado American Progress, que representa a ideologia do progresso na forma de uma mulher dirigindo-se para o Oeste (para onde se dirigia o sonho americano de expansão nesses tempos). 0 desenho era impresso em guias de viagem desse tempo. A pintura mostra uma paisagem que, a leste (lado direito do quadro), representa o progresso na forma de locomotivas, barcos, cidades e outros símbolos do desenvolvimento humano; enquanto a oeste (lado esquerdo), surgem animais selvagens, indígenas e descampado. Como destaca Jake Colberg (2012), a pintura tem uma variação de luminosidade: a forte luz do leste vai gradualmente se escurecendo até o oeste, que encontra-se coberto por nuvens escuras, do mesmo modo como "as suaves colinas do leste dão lugar a montanhas escarpadas na medida em que a pintura a se move para o lado esquerdo, do oeste". É fácil adivinhar a simbologia: "o Oriente é caloroso e acolhedor, enquanto o Ocidente é escuro e ameaçador". Nesse cenário, a figura da mulher é especialmente interessante. Semelhante a um anjo, a luz que se projeta para cima e para o leste é exalada claramente por ela, que se move para o oeste, iluminando o caminho, transformando o deserto selvagem em civilização. Ela representa 0 avanço tecnológico da luz da razão que deve chegar ao Ocidente como forma de liquidar de forma definitiva essa fronteira nacional, um pensamento que foi muito difundido na época. 


\section{A promessa da vida eterna}

Um dos pontos centrais da religião sempre foi a promessa da imortalidade. Tal promessa é, agora, assumida pela tecnologia. A longevidade, o prolongamento da vida ou a cura da morte têm sido colocadas entre suas metas centrais. Muitas vezes tal promessa de imortalidade se resume ao projeto de expansão da mente em direção à matéria inerte, como sugere o projeto Omega Points, defendido por Frank J. Tipler, cuja cosmologia é inspirada em Teilhard de Chardin e cuja proposta se enquadra em uma escatologia física de cenário alargado, ou seja, um "estudo da evolução futura do universo baseada na física conhecida” (SANBERG, 2015, p. 17) mas que ofereça perspectivas em escala planetária. Nesse caso, informação infinita e poder infinito de processamento da nova inteligência são associados à imagem de Deus: "Omega Points será um tempo benevolente no qual todos os mortos ressuscitarão, produzindo uma interminável vida no além virtual" (SANBERG, 2015, p. 17). Há, nesse caso, uma nova teologia nascendo. Uma teologia cheia de excessos ficcionais, é verdade, mas que indica as bases da nova ideologia tecnicista de nossos dias.

A expansão da inteligência para além do corpo humano, primeiro para as máquinas e depois para a matéria inerte em geral, é outra etapa desse processo, e ela inaugura uma nova perspectiva panvitalista em movimento no trans-humanismo: Ray Kurzweil (2013) se refere ao esforço de "acordar" a matéria inerte do universo inculcando-lhe algum tipo de inteligência. A tecnosfera seria, assim, ampliada de forma radical a partir das pesquisas da neurociência e da inteligência artificial. A inteligência teria assim, no universo da matéria morta, o seu último degrau, em vista da dominação humana do cosmos. Ao expandir a vida para o espaço, superando os limites impostos pela biosfera e convertendo a matéria em substância mental, o ser humano encontraria também um sentido expandido para sua vida: o próprio universo. Tarefa interplanetária, interestelar e intergaláctica, essa seria, finalmente, a meta da humanidade. Se "a pura matéria carece de valor inerente" (SANDBERG, 2015, p. 15) então uma matéria na qual foi inserida alguma espiritualidade (na forma de atividade mental) também será uma matéria com 
mais "valor", ou até mesmo com capacidade de "valorar", já que a atividade racional é a base da atividade moral.

\section{Considerações finais}

O mito do progresso técnico, aliado à utopia tecnológica, tem sido divulgado de forma insistente, a fim de demonstrar que os benefícios de tais procedimentos são mais evidentes do que seus potenciais riscos e perigos. A posição dos trans-humanistas, contudo, não é totalmente ingênua. Muitos de seus teóricos dedicam boa parte do seu tempo para discutir tais riscos, embora seu ponto de partida seja a crença de que todos os riscos e os males são preferíveis diante dos bens possíveis. A meta-narrativa do progresso, por isso, impede uma interpretação como a proposta por Jonas, Fukuyama, Sandel ou Habermas, geralmente acusados de bioconservadores.

Um exemplo dessa ambiguidade diz respeito ao tema da imortalidade: por um lado ela se oferece como um sentido da vida e, por outro, ela absorve os riscos que vêm comprometendo as condições para que a vida continue existindo, resultado de um processo amplo de extinção dos organismos e de esgotamento dos recursos naturais, sem os quais a vida humana não é possível. A ferramenta que cura é, portanto, a mesma que adoece e extingue. A sede de imortalidade pode colocar em xeque a própria vida do ser mortal que somos. Nesse sentido, o novo Adão pode ser também um novo Frankenstein.

Como vimos, o entusiasmo dos arautos do trans-humanismo e da obrigação moral de melhoramento do ser humano seculariza muitos dos antigos ideais religiosos. Antes que isso seja um prejuízo, trata-se de uma evidente vantagem para um movimento que pretende se expandir e convencer novos "adeptos": o discurso religioso se torna, assim, um importante aliado na construção de uma argumentação favorável ao avanço das pesquisas, na medida em que pode ampliar os apoios, não só entre os acadêmicos como, sobretudo, entre a população em geral. Cabe à filosofia e à teologia enfrentarem criticamente esse movimento e discutir a sério as suas premissas, seja porque elas podem de fato vir a se realizarem, seja porque elas oferecem a chance 
de retomada de alguns dos temas centrais de nossa tradição de pensamento e, inclusive, de nossas crenças.

\section{Referências}

BURDETT, M. S. The Religion of Technology: transhumanism and the myth of progress. In: MERCER, C.; TROTHEN, T. J. (eds.). Religion and transhumanism: the unknown future of human enhancement. Santa Barbara; Denver; Oxford: Praeger, 2015. p. 131-147.

COLBERG, J. Stabbing Westward: An Analysis of John Gast's "American Progress". 30 nov. 2012. Disponível em: 〈https://goo.gl/db314N〉. Acesso em: 28 mar. 2016.

FUKUYAMA, F. The world's most dangerous idea. Foreign policy, Sept./Oct. 2004.

GORDIJN, B.; CHADWICK, R. (eds.). Medical Enhancement and Posthumanity. [London]: Springer, 2008.

HAUSKELLER, M. A cure for humanity: The transhumanisation of culture. TransHumanities, v. 8, n. 3, p. 131-147, 2015.

HERBRECHTER, S. Posthumanism: a critical analysis. London: Bloomsbury, 2013. HOTTOIS, G. Le transhumanisme est-il un humanisme? Bruxelles : Académie royale de Belgique, 2014.

JONAS, H. O princípio responsabilidade: ensaio de uma ética para a civilização tecnológica. Trad. Marijane Lisboa, Luiz Barros Montez. Rio de Janeiro: Contraponto : Ed. PUCRio, 2006.

JONAS, H. Técnica, medicina e ética. Sobre a prática do Princípio Responsabilidade. Tradução GT Hans Jonas da ANPOF. São Paulo: Paulus, 2013. (Col. Ethos)

JONAS, H. Pensar sobre Dios y otros ensayos. Trad. Angela Ackermann. Barcelona: Herder, 1998.

Jonas, H. Technik, Medizin und Ethik: Zur Praxis des Prinzips Verantwortung. Frankfurt: Suhrkamp, 1985. 
KURZWEIL, R. How to create a mind: the secret of human thought revealed. New York: Penguin, 2013.

MIDGLEY, M. The Myths we live by. London: Routledge, 2003.

MORE, M. The extropian Principles 2.5. Extropy 11, $2^{\text {nd }}$ Half, 1993. Disponível em: 〈http://www.aleph.se/Trans/Cultural/Philosophy/princip.html>. Acesso em: 27 mar. 2016.

NAAM, R. More than human: embracing the promise of biological enhancement. New York: Broadway Press, 2005.

NIETZSCHE, F. Humano, Demasiado Humano I. Trad. Paulo César de Souza. São Paulo: Cia. das Letras, 2000.

RANISCH, R.; SORGNER, S. L. (eds.). Post-and Transhumanism: An introduction. Frankfurt am Main: Peter Lang Edition, 2014. v. 1.

SANDBERG, A. Transhumanism and the Meaning of life. In: MERCER, C.; TROTHEN, T. J. (ed.) Religion and transhumanism: the unknown future of human enhancement. Santa Barbara; Denver; Oxford: Praeger, 2015. p. 3-22.

SEUNG, S. Connectome: How the Brain's Wiring Makes Us Who We Are. New York: Houghton Mifflin Harcourt, 2012.

TERASEM. The truths of Terasem. (C) 2002/2012. Disponível em: <http://terasemfaith.net/beliefs/> Acesso em: 27 mar. 2016.

WIESING, U. The history of medical enhancement: from restitutio ad integrum to transformatio ad optimum. In: GORDIJN, B.; CHADWICK, R. (eds.). Medical Enhancement and Posthumanity. [London]: Springer, 2008. v. 2, p. 9-24.

Recebido: 30/01/2017

Received: 01/30/2017

Aprovado: 06/08/2017 Approved: 08/06/2017 